\title{
Unusual Expansive Mass in the Thyroid Cartilage
}

\author{
Amaya Roldán-Fidalgo ${ }^{*}$, Jose Ramón Secades, Javier Ibarra², Helena Sarasibar ${ }^{3}$ \\ ${ }^{1}$ Otorhinolaryngology Department, Hospital Son Llàtzer, Palma, Spain \\ ${ }^{2}$ Pathology Department, Hospital Son Llàtzer, Palma, Spain \\ ${ }^{3}$ Neuroradiology Department, Hospital Son Llàtzer, Palma, Spain \\ Email: *amaya.roldan@hsll.es
}

How to cite this paper: Roldán-Fidalgo, A., Secades, J.R., Ibarra, J. and Sarasibar, H. (2018) Unusual Expansive Mass in the Thyroid Cartilage. International Journal of Otolaryngology and Head \& Neck Surgery, 7, 43-46.

https://doi.org/10.4236/ijohns.2018.72006

Received: February 8, 2018

Accepted: March 13, 2018

Published: March 16, 2018

Copyright (C) 2018 by authors and Scientific Research Publishing Inc. This work is licensed under the Creative Commons Attribution-NonCommercial International License (CC BY-NC 4.0).

http://creativecommons.org/licenses/by-nc/4.0/

\begin{abstract}
Introduction: Giant cell tumor of the larynx is an uncommon entity with only 42 reported cases in the literature, of which 32 involved the thyroid cartilage. These tumors most commonly occur in the epiphysis of the long bones of female patients in the third decade. Case Report: We present a 57-year-old man with hoarseness and a growing anterior neck mass for the past 5 months. Endoscopic examination revealed a submucosal swelling of the left supraglottic area. CT and MRI of the larynx showed a large, expansive mass at the left thyroid cartilage. The anterior neck mass was biopsied and histopathological analysis showed mononuclear cells and homogeneously distributed multinucleated giant cells. A giant cell tumor of the larynx was suspected. The patient underwent a supracricoid subtotal laryngectomy. Conclusion: Giant cell tumor of the larynx is an uncommon entity, with very few cases reported in the literature. These tumors should be included in the differential diagnosis of a patient with hoarseness and anterior neck swelling. There is no consensus regarding the management, although surgical excision is the most frequently employed treatment with excellent outcomes.
\end{abstract}

\section{Keywords}

Giant Cell Tumor, Larynx, Thyroid Cartilage

\section{Introduction}

Giant cell tumor of the larynx (GCTL) is an uncommon entity with only 42 reported cases in the literature. GCTL is typically found in the epiphysis of the long bones of female patients in the third decade. In the head and neck area, it usually occurs in the sphenoid, temporal and ethmoid bones, and rarely presents 
larynx involvement [1]. The thyroid cartilage is the most frequently affected laryngeal structure $(21.6 \%)$, followed by the cricoid cartilage (9.26\%), the epiglottis $(2.6 \%)$ and soft tissues of the larynx (2.6\%) [2].

\section{Case Report}

A 57-year-old man was referred to the hospital for evaluation of hoarseness and a growing anterior neck mass for the past 5 months. The patient had no smoking history and no prior occupational exposure. The physical examination showed a painless, indurated mass, adherent to deep planes in the left anterior portion of the neck. A nasopharyngolaryngoscopy was performed and revealed a submucosal swelling of the left supraglottic area.

A contrast-enhanced CT (Figure 1(A)) and a coronal FSE T2-weighted MRI (Figure 1(B)) showed a large, hyper-intense and expansive mass in the left thyroid cartilage lamina, with radiological signs of low aggressiveness. The mass surpassed laryngeal midline and presented no invasion of the strap muscles or surrounding soft tissue.

A fine needle aspiration cytology (FNAC) of the anterior neck mass was performed. Cytopathological analysis showed mesenchymal cells in contact with osteoclastic-type multinucleated giant cells. A giant cell tumor of the larynx was suspected.

The case was discussed in a Head and Neck Cancer interdisciplinary committee. Supracricoid subtotal laryngectomy was proposed and performed. The pathology analysis showed a giant cell tumor of the left thyroid cartilage. Macroscopy revealed a homogenous nodular mass with central hemorrhagic focus. Microscopy showed a cellular neoplasm with numerous uniformly distributed osteoclastic-type giant cells separated by mononuclear cells in a vascular stroma (Figure 2).

The patient started speech and swallowing rehabilitation a week after surgery
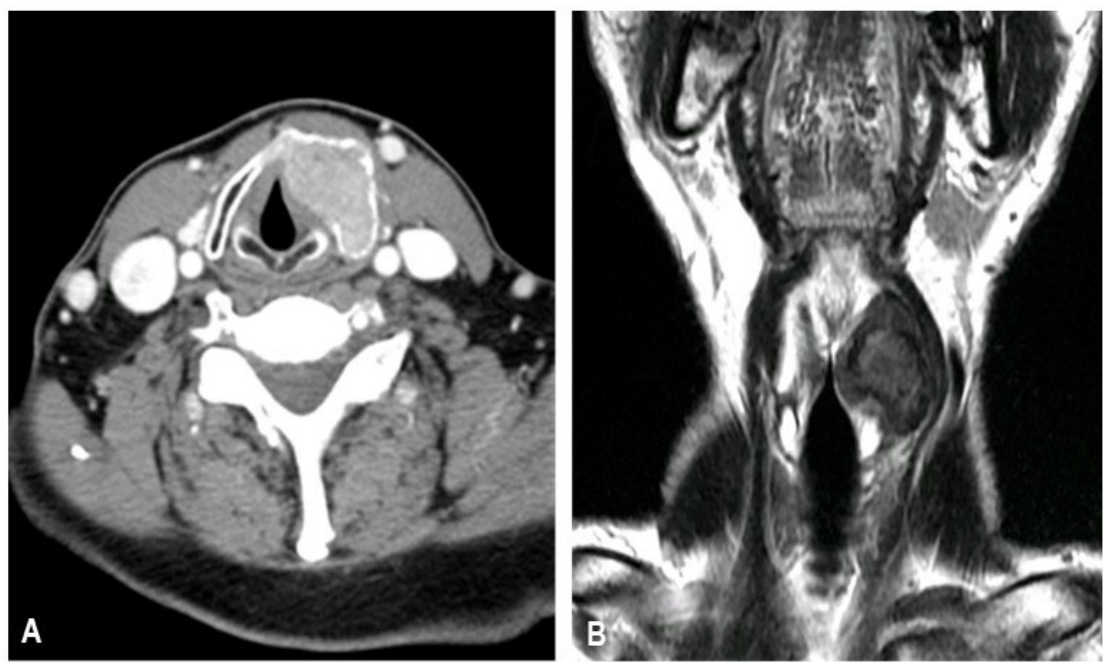

Figure 1. A contrast-enhanced CT (A) and a coronal FSE T2-weighted MRI (B) showed a large, hyper-intense and expansive mass in the left thyroid cartilage lamina. 


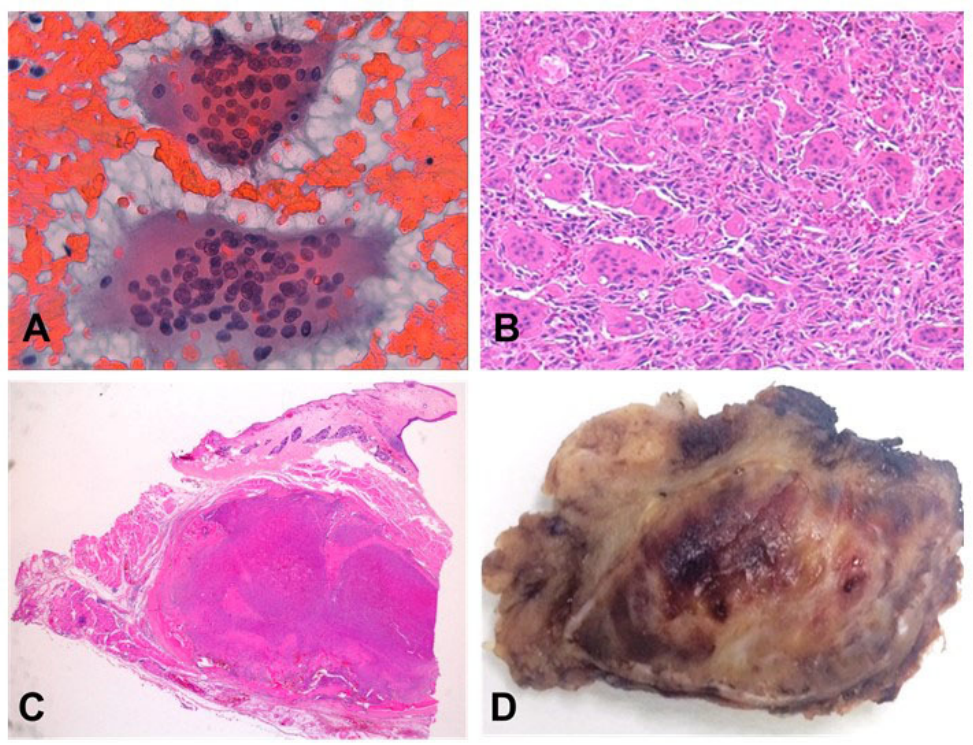

Figure 2. Multinucleated giant cells (A), osteoclastic-type giant cells separated by mononuclear cells in a vascular stroma (B). Histological (C) and macroscopy (D) correlation of an expansive giant cell tumor in the left thyroid cartilage.

and achieved normal laryngeal function two months later, speaking and eating normally. No evidence of recurrence or metastasis was observed at a ten month follow-up.

\section{Discussion}

Giant cell tumor of the larynx is an uncommon entity with 42 cases reported in the literature, of which 32 involved the thyroid cartilage [1]. This tumor is usually benign but can be locally aggressive, recur (25\% of cases), and occasionally produce pulmonary metastasis [2] [3].

GCTL should be included in the differential diagnosis of a patient with hoarseness and anterior neck swelling. The differential diagnosis of a mass in the thyroid cartilage area includes diseases like chondroblastoma, chondrosarcoma, osteoblastoma, giant cell-rich osteosarcoma, foreign body reaction, brown tumor of hyperparathyroidism or GCTL [1] [4]. Imaging studies are not usually sufficient to differentiate these entities, so it is imperative to perform histological examination in order to reach a diagnosis [1].

A mixture of multinucleated giant cells and mononuclear cells in fibroblastic rich, loose, hemorrhagic, vascular stroma is typical of GCTL [5]. Giant cell nuclei are strikingly similar to mononuclear cells. In giant cell tumors the mononuclear component expresses alkaline phosphatase, receptor activator of nuclear factor kappa-B ligated (RANKL) and markers of osteoblast lineage [5].

There is no consensus regarding the management, although surgical excision, ranging from local excision to total laryngectomy is the most frequently employed treatment with excellent outcomes. Other treatments employed were radiation with or without chemotherapy, and systemic denosumab (a monoc- 
lonal antibody against the RANK ligand) [1].

\section{Conclusion}

Giant cell tumor of the larynx is an uncommon entity, with very few cases reported in the literature. There is no consensus regarding the management, although surgical excision is the most frequently employed treatment. These tumors should be included in the differential diagnosis of a patient with hoarseness and anterior neck swelling.

\section{Conflict of Interest}

No potential conflicts of interest have to be disclaimed. Informed consent was obtained from the patient for publication of this case report and any accompanying images.

\section{References}

[1] Arndt, A., LeBlanc, R. and Spafforf, P. (2017) A Large Giant Cell Tumor of the Larynx: Case Report and Review of the Literature. Journal of Otolaryngology-Head \& Neck Surgery, 46, 26. https://doi.org/10.1186/s40463-017-0198-y

[2] Yancoskie, A.E., Frank, D.K., Fantasia, J.E., Savona, S., Eiseler, N., Rede, I. and Kahn, L.B. (2015) Giant Cell Tumor of the Larynx Treated by Surgery and Adjuvant Denosumab: Case Report and Review of the Literature. Head and Neck Pathology, 9, 447-452. https://doi.org/10.1007/s12105-015-0622-4

[3] Nora, J., Okochi, Y., Watanabe, F. and Saiki, T. (2014) Laryngeal Giant Cell Tumor; a Case Report and Review of the Literature. Case Reports in Otolaryngology, 15.

[4] Le, T., Young, K. and Chow, B. (2012) Giant Cell Tumor of the Larynx; a Case Report with Discussion of Radiologic and Histologic Features. Applied Radiology, 41, 29A-D.

[5] Reid, R., Banerjee, S.S. and Sciot, R. (2002) Giant Cell Tumors. In: Fletcher, C.D.M., Unni, K.K., Mertens, F., Eds., World Health Organization Classification of Tumors. Pathology and Genetics of Tumors of Soft Tissue and Bone, IARC Press, Lyon, 309-313. 